\title{
Mídias Sociais como ferramenta de apoio às práticas integrativas em saúde na área de plantas medicinais
}

\author{
Kellen Miranda Sáa, ${ }^{\mathrm{a},}$, Amélia Ramos Freire ${ }^{\mathrm{b}}$, Francilene Caetano ${ }^{\mathrm{b}}$, Karla do Nascimento \\ Magalhães $^{c}$, Sueli Maria de Araújo Cavalcante ${ }^{\mathrm{d}}$, Mary Anne Medeiros Bandeira ${ }^{\mathrm{e}}$ \\ ${ }^{\text {a}}$ Horto de Plantas Medicinais Francisco José de Abreu Matos, Universidade Federal do Ceará, Fortaleza, CE, Brasil \\ ${ }^{\mathrm{b}}$ Programa Farmácias Vivas - Horto de Plantas Medicinais Francisco José de Abreu Matos, \\ Universidade Federal do Ceará, Fortaleza, CE, Brasil \\ ${ }^{\mathrm{c}}$ Faculdade de Educação, Universidade Federal do Ceará, Fortaleza, CE, Brasil d Departamento de Farmácia, \\ Universidade Federal do Ceará, Fortaleza, CE, Brasil; CEATOX/IJF, Prefeitura Municipal de Fortaleza, \\ Fortaleza, CE, Brasil \\ ${ }^{\text {e}}$ Departamento de Farmácia, Universidade Federal do Ceará, Fortaleza, CE, Brasil
}

Histórico do Artigo
Recebido em:
15/11/2017
Aceito em:
05/03/2018
Palavras-chave:
Mídias sociais; terapias
complementares;
Internet; fitoterapia.

Histórico do Artigo Aceito em: Palavras-chave: complementares; Internet, fitoterapia.

Palavras-chave:

Social media; complementary therapies; Internet; phytotherapy.

\begin{abstract}
RESUMO
A universidade se insere na Política Nacional de Plantas Medicinais e Fitoterápicos (PNPMF) como instrumento estratégico para a promoção da educação e da saúde através do ensino, pesquisa e extensão. Essa pesquisa descreve o desempenho de uma mídia social de um projeto de extensão universitária em fitoterapia com foco na melhoria da qualidade de vida e promoção do uso racional de plantas medicinais, no período de janeiro de 2014 a janeiro de 2016. Trata-se de um estudo de caso, de natureza aplicada com abordagem qualitativa, de cunho exploratório e descritivo, elaborado a partir da investigação dos dados etnográficos e administrativos fornecidos pela mídia social analisada. Percebeu-se que a mídia social obteve alcance em nove países, sendo prevalente o público feminino (70\%) com faixa etária variando de 25 a 34 anos. As publicações com inserção de vídeos e/ou citações de órgãos como Ministério da Saúde e Anvisa obtiveram melhor aceitação. Além disso, a mídia social possibilitou interação rápida, precisa e eficaz.
\end{abstract}

Social media as a tool to support integrative practices in health in the medicine plants area

\section{ABSTRACT}

The university is part of the National Policy of Medicinal Plants and Phytotherapy (PNPMF) as a strategic instrument for the promotion of education and health through teaching, research and extension. This research describes the performance of a social media of a university extension project in phytotherapy focused on improving the quality of life and promoting the rational use of medicinal plants, from January 2014 to January 2016. It is a case study of an applied nature with a qualitative, exploratory and descriptive approach, based on the investigation of the ethnographic and administrative data provided by the analyzed social media. It was noticed that the social media reached reach in nine countries, being prevalent the female audience $(70 \%)$ with age range varying from 25 to 34 years. The publications with insertion of videos and / or quotes from organs such as the Ministry of Health and Anvisa obtained better acceptance. In addition, social media has enabled rapid, accurate, and effective interaction.

\section{Introdução}

A disseminação da informação é fundamental para o processo de educação. Segundo os estudos de Velho e colaboradores (1), ocorre um movimento natural em direção a uma área de estudo chamada Comunicação em Saúde, que integra Ciências da Comunicação e Saúde Pública, estabelecendo-se como forma de prover informações aos indivíduos dentro de um processo educativo com vistas a proporcionar meios de

\footnotetext{
*Autor correspondente: kellenmiranda@ufc.br (K. M. Sá)
} 
partilhar conhecimentos e práticas para a promoção da saúde e do autocuidado. Os meios e métodos utilizados para a difusão desse conhecimento são fatores decisivos para o êxito.

Conforme ressaltam Andriola (2) e Lima et.al. (3), a aprendizagem é um processo, através do qual conhecimentos, habilidades, competências e valores são adquiridos ou modificados. Falkenberg (4) coloca que as práticas de educação em saúde envolvem três segmentos de atores prioritários: profissionais de saúde, que valorizem a prevenção e a promoção tanto quanto as práticas curativas, gestores que apoiem esses profissionais e população que necessita construir seus conhecimentos e aumentar sua autonomia nos cuidados, individual e coletivamente. Almeida (5) ressalta que, com o surgimento de novos meios de comunicação, entre os anos 1990 e 2000, e, consequentemente, de outras formas de interação social, cresceu a necessidade de se voltar o olhar para a relação entre duas áreas do conhecimento e entender como as Novas Tecnologias da Informação e Comunicação podem ser instrumentos eficazes na difusão de uma educação para a saúde como um exercício de cidadania.

O uso das redes sociais pelas organizações da sociedade civil surge como uma estratégia de representatividade para a promoção de suas atividades e mobilização em favor dos assuntos relacionados à organização e ao público a que se destinam, configurando-se como alternativas para veicular suas ações e propor suas visões de mundo (6).

As universidades, enquanto instituições de Ensino Superior, têm, com o uso das redes sociais, importante apoio para a disseminação do conhecimento científico, onde os programas de extensão universitária podem atuar plenamente. Fernandes (8) caracteriza a universidade como uma instituição criada para atender às necessidades de um país e a extensão universitária importante meio para a formação de um profissional cidadão. Nesse sentido, a extensão universitária, como processo educativo, cultural e científico, que articula o Ensino e a Pesquisa de forma indissociável e viabiliza a relação transformadora entre universidade e sociedade (7), configura-se como importante meio para a consolidação de políticas públicas vigentes no Brasil, dentre elas, a Política Nacional de Plantas Medicinais e Fitoterápicos na área da saúde. Conforme assevera Souza (9), ao tratar dos principais conceitos e modelos de análise de políticas públicas, as instituições influenciam os resultados das políticas públicas e tornam o curso de certas políticas mais fáceis do que outras.

Assim, ao delegar às universidades, a tarefa da formação e capacitação dos profissionais de saúde e demais envolvidos desde o cultivo à distribuição das plantas medicinais, a Política Nacional de Plantas Medicinais e Fitoterápicos (PNPMF) (10) obteve importantes meios para a sua disseminação. Tal afirmativa é respaldada pelos estudos de Sá (11) quando afirma que o momento atual exige profissionais de saúde capacitados ainda na graduação para atuarem em fitoterapia para que a PNPMF finalmente seja consolidada como deve ser nos sistemas de saúde. Assim, a universidade se insere nessa política através da pesquisa, da promoção da educação superior e das ações de extensão, com a transmissão do conhecimento cientificamente validado de plantas medicinais para a comunidade, proporcionando o uso racional.

O uso das plantas medicinais como terapêutica é conhecido há séculos, e sua maior transmissão se deu através das trocas de informações passadas de geração em geração, principalmente nas comunidades tradicionais. Porém, segundo Marinho (12), esse conhecimento tende à redução ou mesmo ao desaparecimento, quando sofre a ação inexorável da modernidade. A internet, sendo um sistema mundial de redes interligadas, tornou-se um dos meios mais simples e rápidos de divulgação desses conhecimentos, acompanhando o crescente interesse da população por formas mais saudáveis de cuidar 
da saúde. Entretanto, nesse amplo universo, é possível encontrar diversos conteúdos de teor não científico que induzem ao uso irracional de plantas medicinais. Nele, impera a novidade e a valorização ao estrangeiro, exótico, principalmente nos blogs e mídias sociais, com a personificação das informações através de figuras públicas de amplo impacto, as chamadas "influenciadoras digitais".

Plantas medicinais exóticas e potencialmente tóxicas, bem como seus extratos e óleos essenciais (fitoterapia/aromaterapia) são divulgados diariamente com pouca ou nenhuma ênfase aos efeitos adversos, doses e/ou formas adequadas de uso. Tal situação, aliada à ideia errônea de que plantas medicinais são naturais e não causam malefícios, representam potencial risco à saúde da população, necessitando que fontes seguras de informação sejam mais bem divulgadas.

Assim, partindo-se da hipótese de que as mídias sociais são, atualmente, importantes ferramentas para disseminar informações entre diversas culturas dado o amplo alcance, a pesquisa objetivou descrever o desempenho e ações de um projeto de extensão universitária, que utiliza uma mídia social (rede social) para ampliação das ações com foco nas práticas integrativas em saúde na área da fitoterapia/aromaterapia.

\section{Material e métodos}

Trata-se de um estudo de caso, de natureza aplicada, com abordagem qualitativa, de cunho exploratório e descritivo, elaborado a partir da investigação dos dados fornecidos pelo objeto do estudo, uma página pública de uma mídia social gratuita (Facebook) pertencente a um projeto de extensão em saúde de uma Instituição Federal de Ensino Superior (IFES), cujo link de acesso é https://www.facebook.com/farmaciavivaufc/.

A pesquisa, para fins metodológicos, descreve o desempenho dessa mídia social no período de janeiro de 2014 a janeiro de 2016. Segundo Rodrigues (13), as redes sociais, no contexto da internet, são ambientes virtuais onde as pessoas podem se associar umas às outras, a fim de trocar experiências, ideias, compartilhar informações ou simplesmente conversar. Conforme Gil (14), uma pesquisa descritiva objetiva descrever as características de determinada população ou fenômeno ou relações entre variáveis. $\mathrm{O}$ estudo pode ser considerado descritivo por procurar entender o desempenho da mídia social gratuita utilizada no projeto de extensão. Quanto ao meio, é um estudo de caso, pois Yin (15) caracteriza o estudo de caso como uma pesquisa empírica que investiga um fenômeno contemporâneo inserido no contexto de vida real, principalmente, quando os limites entre o fenômeno e o contexto não estão claramente definidos. Gil (14) descreve estudo de caso como um estudo exaustivo que permite um conhecimento amplo e detalhado de um ou poucos objetos.

O projeto de extensão, cuja mídia social deste estudo faz parte, existe desde o ano de 1983, no Ceará, tendo como objetivo levar o conhecimento científico sobre plantas medicinais nordestinas e adaptadas para a comunidade através da implantação de hortas comunitárias e capacitação em serviço. Em 2012, o projeto passou a realizar uma Feirinha da Planta Medicinal às sextas-feiras, contando com uma Página em uma mídia social gratuita (rede social) de amplo alcance para divulgação de suas atividades: serviços gratuitos à comunidade, aferição de pressão e glicemia, orientação farmacêutica, orientação agronômica, bem como visitas guiadas, oficinas e palestras sobre plantas medicinais.

A pesquisa buscou descrever os dados de desempenho fornecidos pela mídia social e registros públicos deixados pela comunidade externa atendida na página. Os registros públicos foram categorizados e selecionaram-se as categorias 'satisfação', porque possibilitam ao administrador da mídia compreender o processo de aceitação das 
publicações e 'uso de plantas medicinais', bem como o grau de entendimento da comunidade sobre plantas medicinais, riscos, tipos de uso, dúvidas, entre outros mais relacionados ao objetivo do projeto e de interesse em saúde.

\section{Resultados e discussão}

A investigação preliminar demonstrou que a página da mídia social fornece diversos mecanismos administrativos importantes para acompanhamento e planejamento de ações estratégicas, sendo todos de fácil utilização e visualização, tais como: gráficos, planilhas, tabelas, horários de maior pico de acesso dos internautas, dicas de publicações, entre outros. Esses mecanismos possibilitaram a análise dos dados no período de Janeiro de 2014 a Janeiro de 2016, perfazendo um total de 24 meses de acompanhamento.

No período da pesquisa, a página contava com 1875 seguidores no total até o dia 21 de janeiro de 2016, o que resultou em uma média de 78 seguidores/mês. Isso, teoricamente, deveria significar o número de pessoas que, a cada nova publicação realizada pelo programa de extensão, visualizaria instantaneamente as notícias em sua própria página pessoal da rede social. Entretanto, isso não pode ser afirmado, pois redes sociais comumente utilizam algoritmos para que uma determinada publicação chegue ao usuário de acordo com seus interesses/relevância e não a cada nova postagem do administrador. Conforme afirma Rodrigues (13), algoritmos são diferentes combinações de duas ideias básicas, em que a primeira é relacionar pessoas com interesses comuns e a segunda é relacionar pessoas de acordo com suas relações sociais.

A página é aberta aos seguidores e não seguidores da rede social, possibilitando visualização também através de sites de busca. O internauta que está inserido na rede social pode compartilhar com seus amigos e grupos as publicações da página do programa, bem como publicá-las em outras mídias digitais, aumentando ainda mais o alcance.

O projeto de extensão realiza a divulgação da programação das feirinhas através da página da mídia social, com antecedência de cerca de cinco dias, o que resulta em uma demanda média presencial nas feirinhas de, aproximadamente, 32 pessoas com cerca de 100 pessoas/semana no horto medicinal, de maneira geral. Presume-se que parte desse público seja proveniente, exclusivamente, da divulgação na internet. $\mathrm{O}$ alcance médio semanal das publicações, de acordo com relatório fornecido pela mídia, chega a 1500 'internautas', sendo o envolvimento com as publicações do projeto de aproximadamente 118 'internautas', com uma média de quatro 'acessos semanais' (entre seguidores e não seguidores da página). A mídia social forneceu ao administrador da página informações detalhadas sobre as preferências dos usuários da rede que acessaram a página, tais como dias da semana em que ocorreram mais visualizações e os horários de maiores picos, possibilitando um melhor planejamento das datas das postagens. A média semanal verificada no período da pesquisa foi de 1815 acessos, que ocorreram, majoritariamente, às quartas-feiras, sendo o horário de maior pico o de 22h (Horário de Brasília), com uma média de 884 acessos. Isso demonstra que a maioria dos seguidores da página, muito provavelmente, trabalha e/ou estuda durante o dia, preferindo o horário noturno para uso da internet, o que coincide com os horários de pico da televisão aberta no Brasil. Tais dados reforçam o que Almeida (5) ressalta: os novos meios de comunicação podem ser instrumentos eficazes na difusão de uma educação para a saúde.

$\mathrm{Na}$ página do projeto, são publicados notícias e vídeos importantes sobre assuntos relacionados às práticas integrativas e complementares em saúde (PICs), agricultura, orgânicos, saúde, ecologia e, principalmente, plantas medicinais e derivados. Quanto 
aos compartilhamentos, reações e comentários (momento em que os internautas, seguidores e não seguidores, participam 'pró-ativamente', através de comentários públicos e compartilhamentos), verificou-se que a popularidade/aceitação aumenta quando são postados vídeos interativos e/ou publicações de órgãos conceituados, tais como Anvisa, Ministério da Saúde, entre outros, bem como notícias de destaque/repercussão em outras mídias relacionadas aos assuntos abordados. Essa constatação ressalta a importância dos conteúdos cientificamente embasados e da procedência desses.

No período analisado (Quadro 1), foram publicados cinco vídeos sobre temas diversos que geraram alcance médio de cerca de 850 seguidores e uma média de 270 visualizações.

Quadro 1: Dados numéricos do alcance das publicações tipo vídeo

\begin{tabular}{|c|c|c|}
\hline Publicação & Alcance & Visualizações \\
\hline Fev. 2015 & 863 & 358 \\
\hline Jun. 2015 & 783 & 311 \\
\hline Ago. 2015 & 979 & 298 \\
\hline Nov. 2015 & 733 & 210 \\
\hline Nov. 2015 & 766 & 176 \\
\hline Total & 4124 & 1353 \\
\hline Média & 824,8 & 270,6 \\
\hline
\end{tabular}

Fonte: Página Feirinha da Planta Medicinal UFC - Facebook.

Verificou-se, também, que o alcance da mídia gratuita é menor que da mídia paga, pois a interface da mídia oferece essa opção ao usuário. Entretanto, o projeto de extensão não possui recursos financeiros destinados a esse fim especificamente.

O Quadro 2 demonstra os países alcançados pela página no período analisado.

Quadro 2: Principais países que acessaram as informações da página

\begin{tabular}{|c|c|c|}
\hline País & Curtidas da Página & Idioma \\
\hline Brasil & 1839 & Português (Brasil) \\
\hline Itália & 6 & Inglês (EUA) \\
\hline EUA & 5 & Português (Portugal) \\
\hline Portugal & 4 & Espanhol \\
\hline Argentina & 3 & Inglês (Reino Unido) \\
\hline Espanha & 3 & Francês (França) \\
\hline Canadá & 2 & Italiano \\
\hline França & 2 & Espanhol (Espanha) \\
\hline Austrália & 2 & Inglês (Pirata) \\
\hline Reino Unido & 2 & Indonésio \\
\hline
\end{tabular}

Fonte: Página Feirinha da Planta Medicinal UFC - Facebook.

Verificou-se que a página do programa de extensão recebeu acessos provenientes de nove países diferentes. Isso evidencia o alcance das mídias sociais. Sob esse aspecto, podem ser ferramentas de processo de comunicação com vistas à educação e à promoção da saúde em rede (16). Também indica a importância de se publicar em dois idiomas: o português (nativo) e o inglês (língua universal) para possibilitar melhor divulgação/entendimento dos conteúdos. Segundo Lemos (17), a cultura contemporânea, marcada pelas tecnologias digitais, gera novas relações sociais eletrônicas que devem ser consideradas.

O público do período avaliado foi composto por cerca de $70 \%$ de mulheres e de $30 \%$ de homens, sendo a faixa etária feminina mais prevalente a de 25 a 34 anos, correspondendo a cerca de $30 \%$ do total de mulheres da pesquisa. O mesmo ocorreu 
com a faixa etária do público masculino.

A análise das postagens dos internautas na página demonstrou que os comentários são positivos em relação às oficinas presenciais e à página, como pode ser observado: (Internauta 1) - Agora a página está sendo atualizada com mais frequência, isso é muito bom. Os assuntos abordados são interessantes. As oficinas são excelentes, muito proveitosas. Aprendi muitas coisas e já colocamos a teoria em prática, aqui em casa. (Internauta 2) - Muito importante o trabalho de vcs! Os conhecimentos técnicos são passados com simplicidade, instruindo a comunidade! Parabéns! (Internauta 3) - Acho o trabalho de vocês muito interessante. Gostaria de ser uma multiplicadora desse conhecimento na comunidade que trabalho (...). Vocês têm algum trabalho de divulgação nos bairros?(...).

Foram verificadas situações na página em que os próprios internautas publicamente postaram respostas uns aos outros, envolvendo indicação de plantas, em que se constatou a intervenção do farmacêutico moderador.

Outras postagens analisadas foram subdivididas em: a) solicitação de informações sobre o uso de plantas medicinais com poucos estudos científicos; b) solicitação de informações sobre plantas divulgadas na internet. Um desses casos relata o consumo de substâncias amargas de um vegetal desconhecido. A população geralmente tende a não atribuir riscos ao consumo de plantas por acreditar que o natural não faz mal à saúde. Casos de envenenamento são registrados em literatura por uso incorreto de substâncias naturais. Segundo Anderson (18), numa mesma planta, é encontrado um arsenal de componentes ativos, os chamados "fitocomplexos", dos quais um ou mais determinam a ação medicinal principal. Substâncias amargas geralmente estão associadas à presença de alcaloides e, segundo Matos (19), alcaloides tipo pirrozilidínicos podem provocar síndrome de Budd-Chiari (doença venoclusiva), que pode evoluir tardiamente para uma cirrose hepática ou câncer do fígado. A orientação oferecida (já que se tratava de morador da cidade) foi procurar o herbário localizado na universidade para realização do reconhecimento botânico, pois seria possível a identificação da espécie e descrição de suas ações medicinais e/ou tóxicas.

No ano de 2015, a planta conhecida como "jaramataia" (Vitex gardneriana Schauer) teve ampla divulgação em uma cidade do nordeste brasileiro por causa de várias curas atribuídas, divulgadas por uma emissora de rádio. Logo, o questionamento chegou à página da universidade. Segundo Lima e França (20), a espécie vegetal é classificada dentro da família Lamiaceae, gênero Vitex, sendo utilizada pela população nordestina como anti-inflamatório e analgésico. Os problemas evidenciados na postagem relacionavam-se à falta de dados botânicos (nome científico da planta utilizada), falta de embasamento científico, bem como a tendência da população em acreditar na cura milagrosa para todas as doenças pregadas por muitos leigos.

Todas as situações evidenciadas demonstraram a posição relevante que as universidades ocupam perante a sociedade como detentora do conhecimento cientificamente validado, colaborando para reforçar o processo educacional através das mídias sociais, o que é embasado por Andriola (2) e Lima et. al. (3) quando 'estes autores' colocam que a aprendizagem é um processo através do qual conhecimentos, habilidades, competências e valores são adquiridos ou modificados.

Pelos resultados obtidos e suas análises, pode-se confirmar o que evidenciou Bustamante (21): nos últimos anos, as mídias sociais alteraram completamente a maneira como as pessoas interagem no âmbito das relações pessoais e profissionais, ganhando destaque por serem mais representativas e eficazes que outros meios de comunicação, sendo importantes ferramentas de marketing de relacionamento, em que as experiências compartilhadas pelos consumidores são cada vez mais utilizadas nas 
decisões das empresas. Nesse sentido, de acordo com Porto (22), interligar comunicação e saúde é atuar no sentido de garantir que esse direito seja atendido e que alcance toda a população, promovendo qualidade de vida e cidadania. Entretanto, ao mesmo tempo, é necessário que essa comunicação seja fundamentada em bases científicas para promover educação, conforme é reforçado por Salci et al. (23), que afirma ser a concepção de educação em saúde tradicionalmente compreendida como transmissão de informações com o uso de tecnologias mais avançadas ou não.

\section{Conclusão}

Concluiu-se que as mídias sociais são ferramentas não tradicionais importantes para democratização das informações cientificamente validadas sobre plantas medicinais e seus derivados, devendo ser consideradas em projetos de saúde. As mídias sociais agregam ampla aceitação do público e possuem mecanismos gerenciais de fácil acesso.

A multiplicidade e a diversidade de mecanismos da interface da mídia social do estudo possibilitou conhecer dados importantes sobre seu desempenho e público alcançado. Cita-se elevado alcance, utilização de linguagem simples, visual/sonora e acessível, favorecendo maior proximidade com o público. Verificou-se, porém, que a modalidade gratuita da mídia limita o alcance a mais internautas. Esse fator deve ser avaliado se a intenção for um alcance ilimitado e com recursos financeiros disponíveis para esse fim.

Salienta-se que os resultados desta pesquisa são referentes a um estudo de caso e novos estudos sobre a temática devem ser realizados para se gerar mais resultados que contribuirão para o aprimoramento de projetos de extensão na área da educação e saúde em plantas medicinais.

\section{Referências}

1. Velho APM, Skura I, Sônia CD. Mídias Sociais e Saúde: analisando a integração dos servidores do hospital universitário de Maringá/PR. Com. \& Merc./UNIGRAN 2014; 3 (8): 04 - 15.

2. Andriola WB. Avaliação do aprendizado discente: estudo com professores de Escolas Públicas. Educ. em Rev. 2012; 46: 141-158.

3. Lima AS, Andriola WB, Tavares WA. Melhorando o processo de ensino e aprendizado em cursos de graduação na área de computação por meio da utilização de edublogs. Revist. Ib-Amer. de Estud. em Educação. 2015; 10: 816-841.

4. Falkenberg MB, Mendes TPL, Moraes EP, Souza EM. Educação em saúde e educação na saúde: conceitos e implicações para a saúde coletiva. Ciênc. Saúde coletiva 2014; 19 (3): 847-852.

5. Almeida MA, Stasiak D. A promoção da saúde nas mídias sociais - Uma análise do perfil do Ministério da Saúde no Twitter. [trabalho conclusão de curso de pós-graduação] Goiânia: Faculdade de Comunicação e Biblioteconomia, UFG; 2012.

6. Borges J, Lessa B, Oliveira L. O papel dos sites de redes sociais nas estratégias comunicativas de organizações da sociedade civil de Salvador-Bahia-Brasil. Observatório (OBS) 2014; 8(3): 183-203.

7. Renex, Forproex, Rede Nacional de Extensão Universitária, Coleção Extensão Universitária vol.I, 2007, Disponível em: http://www.renex.org.br/documentos/Colecao-Extensao-Universitaria/01Plano-Nacional-Extensao/Plano-nacional-de-extensao-universitaria-editado.pdf. Acesso em: 5 dez. 2015.

8. Fernandes MC, Silva LMS, Machado ALG, Moreira TMM. Universidade e a extensão universitária: a visão dos moradores das comunidades circunvizinhas. Educ. rev. 2012; 28 (4): 169-194.

9. Souza C. Políticas Públicas: uma revisão da literatura. Sociologias. [Internet] 2006; 8(16): 20-45.

10. BRASIL. Ministério da Saúde. Secretaria de Ciência, Tecnologia e Insumos Estratégicos, Departamento de Assistência Farmacêutica. Política Nacional de PlantasMedicinais e Fitoterápicos. Brasília: Ministério da Saúde, 2006.

11. Sá KM. A Repercussão da Política Nacional de Plantas Medicinais e Fitoterápicos na Formação 
Superior em Saúde no Estado do Ceará Entre 2006 e 2016. [dissertação] Fortaleza: Pró-reitoria de Pesquisa e Pós-Graduação, Universidade Federal do Ceará; 2016.

12. Marinho MGV, Silva CC, Andrade LHC. Levantamento etnobotânico de plantas medicinais em área de caatinga no município de São José de Espinharas, Paraíba, Brasil. Rev. bras. plantas med. 2011; 13( 2 ): 170-182.

13. Rodrigues PG, Júnior EPFD. (2010). Middlewares e protocolos para redes sociais pervasivas. Monografia (PUC-RJ).

14. Gil AC. Métodos e Técnicas de Pesquisa Social. 6. ed. São Paulo: Atlas, 2008.

15. Yin RK. Estudo de Caso: planejamento e métodos. Tradução Ana Torell. Revisão Técnica Cláudio Damascena. 4 ed. Porto Alegre: Bookman, 2010.

16. Vermelho SC, Velho APM, Bonkovoski A, Pirola A. Refletindo sobre as redes sociais digitais. Educ. Soc. 2014; 35 (126): 179-196.

17. Lemos A; Cunha $\mathrm{P}$ (orgs). Olhares sobre a Cibercultura. Cibercultura. Alguns pontos para compreender a nossa época. Porto Alegre: Sulina, 2003; p. 11-23.

18. Anderson JE, Chang CJ, Mclaughlin JL. Bioative components of Allamanda schottii. J. Nat. Prod. 1988; 51 (2): 307-8.

19. Matos, FJA. Plantas Medicinais: guia, seleção e emprego das plantas usadas em fitoterapia no nordeste do Brasil. 3. Ed. - Fortaleza: Imprensa universitária, 2007. p. 185.

20. Lima CT, França F. Flora Da Bahia: Vitex Tour. ex L.- (LAMIACEAE). $60^{\circ}$ Congresso Nacional de Botânica - BA. 2009.

21. Bustamante TF, Barreto IF. As Mídias Sociais como Ferramenta de Novos Negócios e de Relacionamento com o Cliente: um Estudo de Caso com Empresa de Serviços de Telecomunicações. Revista ADM.MADE. 2013; 17 (1): 60-79.

22. Porto C, Santos E. Facebook e educação: publicar, curtir, compartilhar. EDUEPB. 2014. Disponível em http://static.scielo.org/scielobooks/c3h5q/pdf/porto-9788578792831.pdf.

23. Salci MA, Maceno P, Rozza SG, Silva DMGV, Boehs AE, Heidemann ITSB. Educação em saúde e suas perspectivas teóricas: algumas reflexões. Contexto Enferm. 2013; 22 (1): 224-230. 